\title{
Investigação genético-epidemiológica e molecular da deficiência de G-6-PD em uma comunidade brasileira
}

\author{
G-6-PD deficiency in a Brazilian community: \\ an investigation involving epidemiological \\ genetics and molecular techniques
}

Mariane B. Compri 1

Sara T. O. Saad 2

Antonio Sérgio Ramalho 2

\footnotetext{
${ }^{1}$ Faculdade de Ciências Médicas, Universidade São Francisco. Av. São Francisco de Assis 218, Bragança Paulista, SP 12900-000, Brasil.

2 Departamento de Genética Médica, Faculdade de Ciências Médicas, Universidade Estadual de Campinas. C. P. 6111, Campinas, SP 13081-970, Brasil. dgmfcm@obelix.unicamp.br
}

\begin{abstract}
This paper reports on a study of the G-6-PD deficiency in Bragança Paulista, São Paulo State, Brazil. A total of 4,621 male blood donors were investigated over a 36-month period. Of these, 80 had the G-6-PD deficiency. Molecular analysis was performed on 70 unrelated G-6$P D$ deficients through DNA amplification followed by digestion with restriction enzymes and single strand conformation polymorphism analysis (SSCP). In 98.6\%, the G-6-PD $A^{-}(202 G \rightarrow A)$ mutation was observed through digestion of exon 4 with Nla III. The presence of an uncommon mutation in exon 9 was also observed through SSCP. No case of the Mediterranean variant was observed. These results indicate that the $A^{-}(202 G \rightarrow A)$ variant, almost exclusive, was introduced into the community not only by individuals of African origin, but also by European immigrants, mainly Italian, Spanish, and Portuguese. The Italian contribution in terms of the G-6-PD Mediterranean variant was smaller than its contribution to beta thalassemia, probably due to the Northern Italian origin of these immigrants.
\end{abstract}

Key words Glucosephosphate Dehydrogenase Deficiency; Community Genetics; Medical Genetics; Molecular Biology

Resumo Este trabalho teve por objetivo estudar a deficiência de G-6-PD em uma comunidade do interior do Estado de São Paulo (Bragança Paulista). Durante 36 meses foram selecionados 4.621 doadores de sangue do sexo masculino, detectando-se 80 deficientes em G-6-PD. A análise molecular foi realizada em 70 deficientes não consangüíneos mediante a amplificação de DNA por PCR seguida de digestão por enzimas de restrição e análise de polimorfismo de conformação em hélice simples (SSCP). Em 98,6\% dos casos, foi identificada a mutação G-6-PD A- (202 G $\rightarrow A)$, por digestão do exon 4 com Nla III. Verificou-se a presença de mutação mais rara no exon 9, por SSCP. Não foi constatado caso da variante Mediterrânea. Tais resultados mostraram que a variante $A^{-}$(202 $G \rightarrow A$ ), quase que exclusiva, foi introduzida na comunidade não apenas por descendentes de africanos, como também pelos imigrantes italianos, espanhóis e portugueses. A contribuição italiana em termos da variante Mediterrânea de G-6-PD foi menor do que a sua participação em termos de talassemia beta, provavelmente devido à origem no Norte da Itália.

Palavras-chave Deficiência de Glicosefosfato Desidrogenase; Genética Comunitária; Genética Médica; Biologia Molecular 


\section{Introdução}

A deficiência de desidrogenase de 6-fosfato de glicose (G-6-PD) é a mais freqüente das enzimopatias conhecidas, afetando cerca de 400 milhões de pessoas em todo o mundo. As mais altas prevalências - freqüências gênicas de $5 \%$ a 25\% - são encontradas na África Tropical, Oriente Médio, China, Índia, em algumas áreas do Mediterrâneo e Papua Nova Guiné (Luzzato \& Mehta, 1995).

A G-6-PD (EC 1.1.1.49) é enzima citoplasmática amplamente distribuída entre quase todos os organismos e tecidos. Nos seres humanos, apesar da ampla distribuição, é no metabolismo das hemácias que a G-6-PD exerce a sua função mais importante, ao atuar em uma das vias metabólicas utilizadas por estas células para obtenção de energia. Na reação catalisada pela G-6-PD é produzido o fosfato reduzido de nicotinamida adenina dinucleotídeo (NADPH), substância redutora essencial à proteção das hemácias contra a ação de agentes oxidantes de origem endógena (peróxidos orgânicos) e exógena (drogas, alimentos e elementos atmosféricos). Frente ao exposto, pode-se concluir que a atividade da G-6-PD é indispensável à manutenção da integridade das hemácias e que acentuada deficiência dessa enzima pode produzir sérias alterações metabólicas, sobretudo na presença de substâncias oxidantes. A principal conseqüência dessas alterações metabólicas é a hemólise, determinada fundamentalmente pela precipitação da hemoglobina e formação de corpúsculos de Heinz, pela oxidação dos grupos tiol das enzimas citoplasmáticas e da membrana celular e, secundariamente, pela oxidação de lípides da membrana eritrocitária (Beutler, 1983).

A deficiência de G-6-PD é estudada, portanto, pela Farmacogenética, pela Trofogenética e pela Ecogenética, uma vez que a hemólise pode ser desencadeada em seus portadores pela ação, respectivamente, de fármacos (antimaláricos, sulfonamidas e sulfonas, nitrofuranos e alguns analgésicos e antipiréticos, como a acetanilida, aspirina e talvez a fenacetina), alimentos (leguminosa Vicia fava, embutidos ricos em nitritos) e por fatores do meio ambiente (nitritos voláteis, pólen da $V$. fava, naftalina, azul de toluidina etc.).

Geneticamente, a deficiência de G-6-PD (sistema Gd) é entidade heterogênea, causada por genes que se expressam como caráter recessivo do cromossomo X (região Xq 28). Além da enzima normal $\left(\mathrm{Gd}^{+}\right)$, mais de 400 variantes diferentes foram descritas, a maioria das quais com atividade deficiente $\left(\mathrm{Gd}^{-}\right)$. Tais variantes são agrupadas em cinco classes distintas, com base na atividade enzimática residual (Luzzato \& Mehta, 1995):

- Classe I: associada à anemia hemolítica crônica não esferocítica; 97 variantes, sendo apenas uma polimórfica, por exemplo: variantes Andaloris, Campinas e Sumaré;

- Classe II: deficiência enzimática grave $(<10 \%$ de atividade residual): 122 variantes, sendo 37 polimórficas, por exemplo: variantes Mediterrânea e Union;

- Classe III: deficiência enzimática moderada ( $10 \%$ a $60 \%$ de atividade residual): 103 variantes, sendo 22 polimórficas, por exemplo: variantes Africana ou A- Cantão e Seattle;

- Classe IV: atividade enzimática normal ou ligeiramente diminuída (60\% a $100 \%$ de atividade): 52 variantes, sendo 12 polimórficas, por exemplo: Variante A;

- Classe V: atividade enzimática aumentada (>150\% de atividade): duas variantes, nenhuma polimórfica, por exemplo: variante Verona.

De todas as variantes de G-6-PD com atividade deficiente, as que mostram maior importância pela sua freqüência são: a variante Africana ou $\mathrm{A}^{-}$, que ocorre comumente em descendentes daquele continente, bem como no Sul da Itália, Espanha, Portugal e Península Arábica; a variante denominada Mediterrânea, que é encontrada mais usualmente em italianos, em especial, da Sardenha e da Sicília, em gregos, judeus orientais, árabes e persas; a variante Cantão, freqüente no Sul da China; a variante Seattle, que atinge freqüências polimórficas na Sardenha, Grécia e Sul da Itália, embora tenha sido descrita pela primeira vez nos EUA; e, por fim, a variante Union, encontrada em chineses e no Sul da Itália.

\section{A deficiência de G-6-PD no Brasil}

Nos primeiros estudos que enfocaram populações brasileiras, já foi possível verificar que a deficiência de G-6-PD poderia alcançar proporções consideráveis entre os homens, uma vez que ela é causada por genes recessivos do cromossomo X. De fato, estudos efetuados em diferentes regiões do Brasil constataram prevalências de deficientes de G-6-PD em torno de $10 \%$ entre os homens de ascendência africana. Já entre os homens euro-descendentes dos Estados de São Paulo e do Rio Grande do Sul foram encontradas freqüências de deficientes de G-6-PD em torno de 1\% a 3\% (Lewgoy \& Salzano, 1965; Beiguelman et al., 1968; Saldanha et al., 1969; Azevêdo \& Azevedo, 1974; Marques \& Campos, 1975; Ramalho \& Beiguelman, 1976; 
Azevedo et al., 1978; Ramalho, 1979). Nessa fase anterior ao advento das técnicas de biologia molecular, as variantes de G-6-PD - mais freqüentemente caracterizadas, no Brasil, por exames bioquímicos - foram a Africana ou $\mathrm{A}^{-} \mathrm{e}$ a Mediterrânea.

As primeiras avaliações de morbidade da deficiência de G-6-PD em populações brasileiras foram as realizadas por Azevedo et al. (1978) entre homens afro-descendentes de Salvador, Bahia, e por Sena \& Ramalho (1985) entre homens descendentes de europeus e de africanos em Campinas, São Paulo. No estudo feito em Salvador, os autores concluíram que a deficiência de G-6-PD não é suficientemente grave no Nordeste do Brasil para provocar aumento significativo no número de hospitalizações entre seus portadores, conquanto seja capaz de causar icterícia clinicamente detectável. Da mesma forma, os resultados obtidos por Sena \& Ramalho (1985) indicaram que a deficiência de G-6-PD não determina o aparecimento de alterações clínicas graves na maioria dos enzimopênicos da região de Campinas. Nesse estudo pôde-se constatar ainda que, embora os deficientes de G-6-PD mantenham contato freqüente com fatores ambientais potencialmente hemolíticos - tais como, naftalina, sulfas e outros medicamentos -, a intensidade do contato parece ser insuficiente para desencadear, na maioria dos casos, hemólise importante.

A baixa morbidade da deficiência de G-6-PD observada nesses estudos realizados em Salvador e Campinas deve-se, em grande parte, ao fato de a maioria dos deficientes examinados apresentar a variante Africana ou $\mathrm{A}^{-}$da enzima, mais benigna, pois a deficiência enzimática está limitada às hemácias com mais de cinqüenta dias (Beutler, 1959). Sena \& Ramalho (1985), no entanto, chamaram a atenção para a possibilidade de casos isolados de deficientes de G-6-PD no Brasil poderem manifestar anemia hemolítica aguda importante, até mesmo fatal, na presença de fatores oxidantes fortes, ressaltando a importância da detecção e da orientação preventiva dos enzimopênicos nas populações, sobretudo naquelas em que a probabilidade de encontro da variante Mediterrânea, mais grave, for maior. Por outro lado, a associação entre a deficiência de G-6-PD e a icterícia neonatal, sugerida por investigações realizadas no Estado de São Paulo (Segre, 1971; Ramalho, 1979, 1981; Rivero et al., 1981), foi comprovada estatisticamente na região de Campinas (Garlipp \& Ramalho, 1988).

Mais recentemente, com a introdução em nosso país das técnicas de biologia molecular, a atenção dos pesquisadores voltou-se para a caracterização das mutações causadoras da deficiência de G-6-PD, comprovando-se a predominância das variantes Africana ou A- e Mediterrânea, além da descrição de novas mutações, como é o caso das variantes Lages, São Borja, Farroupilha, Anaheim, Campinas e Sumaré (Saad et al., 1997; Weimer et al., 1998). Esses estudos moleculares foram realizados, em geral, em pacientes detectados em centros universitários.

Do exposto conclui-se que, apesar das várias pesquisas efetuadas concernentes ao assunto, a literatura nacional ainda carece de estudos comunitários sistematizados a respeito da deficiência de G-6-PD, nos quais sejam atingidos os objetivos científicos da Genética Comunitária - delineados por Ten Kate (1998) -, incluindo-se aqui os aspectos demográficos, genético-epidemiológicos e moleculares.

Considerando-se que a deficiência de G-6$\mathrm{PD}$, além de seu aspecto médico, é importante marcador genético de etnias e populações, pode-se pensar que ela também constitui elemento útil para o estudo da composição genética das comunidades brasileiras que foram incorporando, ao longo de sua história, povos das mais diferentes origens e com diversos graus de miscigenação. Até o momento não dispomos de informação, por exemplo, a respeito da prevalência da variante Mediterrânea de G-6-PD em comunidades do interior do Estado de São Paulo, que receberam grandes contingentes de imigrantes italianos. Assim sendo, julgou-se relevante realizar um estudo desse tipo na comunidade de Bragança Paulista, São Paulo.

\section{A comunidade de Bragança Paulista}

Bragança Paulista é uma cidade localizada no interior do Estado de São Paulo, distante apenas $90 \mathrm{~km}$ da capital, e que reúne condições propícias à implantação de programas comunitários. Dentre elas, merecem destaque o seu porte médio (109.863 habitantes, pelo censo de 1995), a heterogeneidade étnica de sua população, as boas condições de saneamento básico e uma Faculdade de Ciências Médicas (Universidade São Francisco), que conta com um setor de Hematologia Clínica e Laboratorial, vinculado à Hemo-Rede (Rede Estadual de Hematologia e Hemoterapia do Estado de São Paulo). Outro fator favorável é a distância de apenas $60 \mathrm{~km}$ da Universidade Estadual de Campinas - UNICAMP, equipada para fornecer assessoria em técnicas laboratoriais mais complexas e especializadas - como, por exemplo, as de Biologia Molecular -, que são imprescindíveis na ca- 
racterização das mutações presentes na comunidade.

Como tantas outras cidades brasileiras, Bragança Paulista teve a sua origem nas proximidades de uma capela, no ano de 1763 . Neste local cresceu o povoado de Conceição do Jaguari, que passou à condição de Vila Bragança no ano de 1797 (Bueno, 1993). Da mesma forma que toda sociedade brasileira da época, esta apresentava, em seu topo, os grandes proprietários rurais, homens brancos e livres, geralmente de origem portuguesa. A população negra era dividida entre escravos e libertos. Em 1836, a população de Bragança Paulista era composta por 7.162 brancos, 2.006 mulatos e 1.236 negros (Martins \& Laurito, 1943).

Na primeira metade do século XIX, Bragança constituía, juntamente com outras cidades da região, o celeiro da capital, pois produzia feijão, milho, arroz e até trigo, além do gado. $\mathrm{O}$ açúcar não teve importância econômica de destaque na região e a lavoura de mantimentos e a pecuária foram as duas principais motivações da economia bragantina. Ademais, a localização de Bragança, próxima ao sul de Minas Gerais, colocou-a na rota do lucrativo e intenso comércio de tropeiros.

Da segunda metade do século XIX em diante, além de a cidade desenvolver o comércio, passou a conviver com a cafeicultura e com os imigrantes europeus. Nos fins do século XIX e início do XX, ocorreu intensificação das imigrações, principalmente italiana e espanhola, tendo sido criada em Bragança, nesta época, a Sociedade Italiana de Socorros Mútuos (1891), a Sociedade Espanhola de Socorros Mútuos 2 de Mayo (1900), a Sociedade Italiana Fatellanga (1898) e a Sociedade Recreativa Italiana (1908) (Bueno, 1993).

Dados do final da década de 30 mostram que a produção de milho e feijão continuou. A pecuária e a suinocultura também representavam, há décadas, parte da economia da cidade, viabilizadas pela topografia e pela influência dos imigrantes europeus. Com a queda do café, intensificou-se o plantio da batata em um ciclo produtivo de cerca de duas décadas, que foi responsável pela fixação da colônia japonesa em Bragança. Com a pavimentação de estradas regionais e a construção da rodovia Fernão Dias, Bragança Paulista foi perdendo importância econômica a partir da década de 50. As cidades próximas mudaram a sua referência econômica para a capital do estado ou para Campinas (Moreira et al., 1997).

Em 1993 foi implantado em Bragança Paulista um programa comunitário de hemoglobinopatias hereditárias, que despertou o interes- se e a participação voluntária da população (Compri et al., 1996; Ramalho et al., 1996). Tendo em vista a composição étnica da comunidade, outra alteração genética que se julgou merecer um programa educacional e preventivo, por intermédio desta pesquisa, foi a deficiência de G-6-PD, um polimorfismo genético humano que tem recebido a atenção da Organização Mundial da Saúde (WHO, 1995; Modell \& Kuliev, 1998).

\section{Casuística e métodos}

O presente trabalho foi realizado de acordo com os artigos 122 a 130 do capítulo XII (Pesquisa Médica) do Código de Ética Médica do Conselho Regional de Medicina do Estado de São Paulo (CREMESP, 1996). Assim, todos os indivíduos examinados participaram voluntariamente da pesquisa após esclarecimento a respeito dos objetivos e consentimento. A pesquisa visou à proteção da saúde pública da comunidade e não tinha qualquer conotação financeira, política ou eugênica. Os indivíduos examinados foram beneficiados pelo estudo, recebendo os resultados dos exames e, sempre que aceita, a orientação genética foi fornecida. $\mathrm{O}$ projeto foi submetido previamente ao Comitê de Ética em Pesquisa da Universidade São Francisco, recebendo parecer favorável.

O trabalho teve início em 1995 e foram selecionados, durante 36 meses, com relação à deficiência de G-6-PD, pelo método de Brewer et al. (1962), 4.621 doadores de sangue do sexo masculino atendidos no Setor de Hematologia Clínica e Laboratorial da Faculdade de Ciências Médicas da Universidade São Francisco, em Bragança Paulista, São Paulo.

Os indivíduos selecionados tiveram a sua deficiência enzimática comprovada pela quantificação da atividade de G-6-PD (Beutler et al., 1989) e pela eletroforese de G-6-PD em acetato de celulose, $\mathrm{pH}=9,0$ (Sparks et al., 1969). Aqueles comprovadamente deficientes de G-6-PD foram submetidos à análise molecular para caracterização das mutações, com o seu DNA genômico extraído pela técnica recomendada por Maniatis et al.(1989).

Por ocasião da análise molecular, os deficientes de G-6-PD receberam orientação a respeito de sua característica genética, bem como uma cartilha didática ilustrada. A investigação da deficiência de G-6-PD também foi oferecida opcionalmente a seus familiares. Mediante entrevista, foram registrados os dados clínicos sugestivos de hemólise (icterícia, escurecimento da urina, transfusões sangüíneas por anemias 
etc.), tal como a origem de seus ancestrais maternos.

Os deficientes de G-6-PD, nos quais a quantificação e a eletroforese da enzima foram compatíveis com as variantes $\mathrm{A}^{-}$ou Mediterrânea, tiveram os exons 4 ou 6 do gene da G-6-PD amplificados pela reação em cadeia da polimerase (PCR) e submetidos à digestão pelas enzimas Nla III e Mbo II, respectivamente (Poggi et al., 1990). Quando a mutação não foi detectada por esse método, realizou-se a análise de polimorfismo de conformação em hélice simples (SSCP) pela técnica descrita por Orita et al. (1989).

\section{Resultados}

Foram selecionados 85 prováveis deficientes de G-6-PD, dentre os quais 80 casos foram confirmados pelos exames bioquímicos específicos. Assim sendo, o índice de positividade na amostra de doadores foi igual a 1,7\% (80/4.621) e a percentagem de erro do teste de triagem utilizado foi estimado em cerca de $6 \%(5 / 85)$.

Dentre os casos confirmados, 70 indivíduos não consangüíneos (60 euro-descendentes e 10 afro-descendentes) foram submetidos à análise molecular, todos sem antecedentes clínicos sugestivos de hemólise. Foram detectados 69 portadores da mutação $\mathrm{A}^{-}(202 \mathrm{G} \rightarrow \mathrm{A})$, nos quais o fragmento de 320 pb resultante da amplificação do exon 4 foi quebrado pela enzima de restrição Nla III em dois fragmentos de 213 pb e 97 pb. A mutação no exon 6, responsável pela variante Mediterrânea, não foi encontrada em nenhum dos doadores investigados. No entanto, foi detectada outra mutação mais rara, cuja análise pelo SSCP mostrou estar presente no exon 9. Tal mutação está sendo investigada pelo seqüenciamento direto desse exon, e os resultados preliminares sugerem a variante Chatam. O portador dessa mutação foi submetido a outros exames laboratoriais (hemograma com contagem de reticulócitos, urina tipo I, dosagem de bilirrubinas e de haptoglobinas), obtendo-se resultados normais.

O portador da provável mutação Chatam possuía ancestrais maternos de origem italiana. Já dentre os 69 portadores da variante $\mathrm{A}^{-}$ $(202 \mathrm{G} \rightarrow \mathrm{A})$, foram referidos ascendentes maternos africanos (38\%), italianos (17\%), espanhóis (13\%), portugueses (7\%), sírio-libaneses (1\%) e brasileiros ou de origem desconhecida (24\%).

\section{Discussão}

O primeiro aspecto a ser discutido em relação ao presente trabalho diz respeito à abordagem da comunidade a partir dos doadores de sangue. Outros grupos de indivíduos poderiam também ter sido escolhidos, tais como estudantes, recrutas do serviço militar, recém-nascidos etc., porém os doadores de sangue apresentam várias conveniências de ordem prática:

a) preponderância de indivíduos do sexo masculino, o que favorece a triagem de uma condição de herança recessiva ligada ao cromossomo $\mathrm{X}$;

b) os indivíduos submetidos à triagem já estão colhendo voluntariamente amostras de sangue;

c) o atual processo de doação de sangue realizado nos hemocentros favorece a heterogeneidade étnica e socioeconômica dos doadores;

d) a doação de sangue ocorre de forma contínua durante todo o ano, permitindo fluxo igualmente contínuo de triagem;

e) a identificação dos doadores deficientes de G-6-PD é recomendada em hemoterapia, o que justifica a triagem sistemática desses indivíduos do ponto de vista da ética médica.

É importante esclarecer que o atual sistema de doação de sangue - voluntário e não remunerado - mudou o perfil social do doador, que não pertence mais quase que exclusivamente às classes socioeconômicas menos privilegiadas, como acontecia há alguns anos atrás. De fato, em extenso levantamento realizado por Paiva e Silva \& Ramalho (1997) no Hemocentro da UNICAMP, constatou-se que o altruísmo é o maior motivador da doação de sangue, pertencendo os doadores a diversas classes socioeconômicas, com preponderância das classes média e média-baixa. No entanto, como o Núcleo de Hematologia e Hemoterapia da USF é o único "banco de sangue" da cidade de Bragança Paulista, mesmo as classes economicamente mais privilegiadas recorrem a ele. Pode-se dizer, portanto, que a amostragem de 4.621 doadores de sangue bragantinos representa satisfatoriamente uma comunidade de cerca de 110 mil habitantes, embora alguns dos seus componentes - como a colônia japonesa, por exemplo - não estejam perfeitamente representados.

Ao analisar os resultados obtidos, chamam a atenção a ausência da variante Mediterrânea de G-6-PD e a presença quase que exclusiva da mutação $A^{-}(202 \mathrm{G} \rightarrow \mathrm{A})$ tanto em deficientes euro-descendentes quanto afro-brasileiros.

A ausência da mutação Mediterrânea permite especulações interessantes, do ponto de 
vista genético-epidemológico, a respeito da deficiência de G-6-PD na comunidade. Em primeiro lugar, tal resultado contraria a suposição de que os estudos moleculares realizados em comunidades pequenas e médias do interior do Estado de São Paulo encontrariam proporções da variante Mediterrânea de G-6-PD superiores às observadas em grandes centros urbanos paulistas, como é o caso, por exemplo, da cidade de Campinas, na qual, por seu caráter cosmopolita, a influência da imigração italiana estaria mais diluída. De fato, Saad et al. (1997), caracterizando molecularmente 150 doadores de sangue deficientes de G-6-PD não consangüíneos de Campinas, São Paulo, encontraram 146 portadores da variante $\mathrm{A}^{-}(202 \mathrm{G} \rightarrow \mathrm{A})(97 \%)$, três portadores da variante Mediterrânea (2\%) e um portador da variante rara Chatam (1\%). Como é possível observar, a proporção de deficientes de G-6-PD com a mutação A- $(202 \mathrm{G} \rightarrow \mathrm{A})$ não diferiu significativamente entre as duas amostras $\left(\mathrm{x}^{2}{ }_{(1)}=0,33 ; 0,50<\mathrm{p}<0,70\right)$, constituindo a quase totalidade dos casos.

Embora possa parecer surpreendente à primeira vista, a ausência da variante Mediterrânea de G-6-PD na comunidade bragantina torna-se compreensível quando se analisa a origem dos imigrantes italianos que vieram para o Estado de São Paulo.

Entre os anos de 1884 e 1944, o Brasil recebeu cerca de 1,5 milhões de imigrantes italianos, que se estabeleceram principalmente nos Estados de São Paulo, Rio Grande do Sul e Paraná (Salzano \& Freire-Maia, 1970). As populações paulistas receberam imigrantes predominantemente de Veneto (Veneza, Pádua, Treviso, Rovigo e Verona), Lombardia (Mântua e Milão) e Emília Romana (Ferrara, Bolonha, Parma e Módena), os quais, de início, estabeleceram-se em grande parte na zona rural, chegando inclusive a fundar alguns núcleos de colonização italiana (Ramalho, 1986). Esses indivíduos provinham, portanto, do Vale do Pó e outras regiões do Norte da Itália, onde a freqüência da deficiência de G-6-PD é significativamente menor que a observada na Sardenha, na Sicília e no Sul da Itália (Beutler, 1994).

Ao contrário do que ocorre com a deficiência de G-6-PD, a talassemia beta é freqüente no Vale do Pó e em outras regiões do norte da Itália (Weatherall, 1972), o que explica a expressiva prevalência $(1,5 \%)$ dessa alteração genética na comunidade bragantina (Compri et al., 1996).

Outro aspecto a ser tomado em conta no presente trabalho é que, na comunidade analisada, a variante A- de G-6-PD não é "característica de descendentes de africanos”, como é refe- rido freqüentemente em textos didáticos usados em nosso país. Dentre os 69 indivíduos com essa variante - classificada morfologicamente por um dos autores do presente trabalho (M.B.C.) -, foram identificados 59 (86\%) como euro-brasileiros e apenas dez (14\%) como afrobrasileiros, levando-se em consideração a cor da pele, as características faciais e a textura do cabelo. Certamente, alguns desses indivíduos receberam, através da miscigenação, componente gênico africano. No entanto, também é preciso atentar para a contribuição dos imigrantes, uma vez que a variante $\mathrm{A}^{-}$de G-6-PD é freqüente em populações do Sul da Itália, da Espanha, de Portugal e da Península Arábica (Luzzato \& Mehta, 1995). De fato, verificandose a origem dos ancestrais das mães dos deficientes de G-6-PD, não apenas ascendentes africanos, mas também europeus e asiáticos, foram referidos. Parece desnecessário comentar que, por se tratar de caráter recessivo do cromossomo X, o gene da deficiência de G-6-PD é transmitido aos indivíduos do sexo masculino por intermédio de suas mães.

Até 1930, os italianos eram os mais numerosos (34\%) entre os imigrantes europeus que vieram para o Brasil, seguidos pelos portugueses (29\%) e pelos espanhóis. Depois de 1930 , somente os portugueses, por não serem considerados propriamente estrangeiros, continuaram migrando em massa para o Brasil. Ainda outros povos, como árabes, judeus e sírio-libaneses migraram para o Brasil, porém em colônias numericamente pequenas (Azevêdo, 1987).

Conforme já foi comentado na parte introdutória deste trabalho, os espanhóis, além dos italianos, tiveram participação importante na formação da comunidade de Bragança Paulista. Entre os anos 1884 e 1944, cerca de 585 mil espanhóis imigraram para o Brasil, muitos dos quais se estabeleceram no Estado de São Paulo (Salzano \& Freire-Maia, 1970). No censo de 1903 foram registrados 5.681 estrangeiros em Bragança Paulista, sendo 4.260 italianos, 938 espanhóis, 286 portugueses e 197 de outras nacionalidades (Cyro Jr. \& Astrino Jr., 1904).

Um estudo molecular recente efetuado na Espanha demonstrou que, apesar de a deficiência de G-6-PD ser entidade genética heterogênea naquele país, a variante $A^{-}(202 \mathrm{G} \rightarrow \mathrm{A})$ é a mais freqüente na população espanhola (Carrons et al., 1997). Esse fato, bem como o encontro entre os espanhóis das variantes G-6-PD Aures e G-6-PD Santa Maria, que são polimórficas na Argélia, demonstram que, no passado, ocorreu significativo fluxo gênico da África para a Europa, através da Espanha. Lembre-se também que, na Idade Média, os conquistadores á- 
rabes (mouros) estabeleceram-se no Marrocos, Argélia, Tunísia e Espanha.

Somando-se os dados do presente trabalho aos de Saad et al. (1997) e de Weimer et al. (1998), é possível constatar grande homogeneidade da população brasileira quanto à notável preponderância da mutação $A^{-}(202 \mathrm{G} \rightarrow \mathrm{A})$ de G-6-PD. Tal homogeneidade em relação a essa variante só é observada na África Tropical, uma vez que na maioria das áreas de alta prevalência dessa enzimopenia, como é o caso do Mediterrâneo, da Índia, do Sudeste Asiático e da China, são encontrados múltiplos alelos polimórficos (Luzzato \& Mehta, 1995).

Realmente, a análise molecular de brasileiros deficientes de G-6-PD tem demonstrado absoluta preponderância da variante $A^{-}(202 \mathrm{G} \rightarrow \mathrm{A})$, com ausência da variante $\mathrm{A}^{-}(680 \mathrm{G} \rightarrow \mathrm{T})$. Curiosamente, a variante $A^{-}(968 \mathrm{~T} \rightarrow \mathrm{C})$ só foi encontrada em 14 deficientes de G-6-PD do Estado do Pará (Hamel \& Saad, 1998). Excetuandose a variante Mediterrânea no Rio Grande do Sul (Weimer et al., 1998), outras mutações da deficiência de G-6-PD não aparecem em proporção significativa nas populações brasileiras. A provável mutação Chatam encontrada no presente trabalho também foi observada em outra família da cidade de Campinas, São Paulo (Saad et al., 1997).

Concluindo esta discussão, é interessante comentar que fração significativa da comunidade de Bragança Paulista - representada pela colônia japonesa - deve ser relativamente pouco afetada pela problemática da deficiência de G-6-PD.

A migração japonesa para o Brasil, iniciada em 1908, ocorreu sobremodo depois da Primeira Guerra Mundial, foi interrompida durante a Segunda e atingiu um total aproximado de $200 \mathrm{mil}$ pessoas. Os japoneses estabeleceram-se principalmente no Estado de São Paulo e mantiveram-se em relativo isolamento (Azevêdo, 1987).

As condições agrícolas da região de Bragança Paulista atraíram muitos imigrantes japoneses, que se dedicaram inicialmente ao cultivo da batata e, posteriormente, à horticultura e ao cultivo de morango, atividades que, juntamente com o comércio, mantêm até os dias atuais. Considerando-se a taxa reduzida de miscigenação com outros grupos étnicos, é possível deduzir que a freqüência de deficiência de G-6-PD entre os bragantinos descendentes de japoneses deve ser bastante baixa, uma vez que em seu país de origem essa enzimopenia afeta apenas 0,1 \% dos homens (Beutler et al., 1989).

\section{Referências}

AZEVÊDO, E. S. \& AZEVEDO, T. F. S., 1974. Glucose-6phosphate dehydrogenase deficiency and neonatal jaundice in Bahia, Brazil. Ciência e Cultura, 26: 1044-1047.

AZEVÊDO, E. S., 1987. Raça: Conceito e Preconceito. São Paulo: Editora Ática.

AZEVEDO, W. C.; SILVA, M. L. F.; GRASSE, C. B. \& AZEVÊDO, E. S., 1978. Deficiência de glicose-6fosfato desidrogenase em pacientes de um hospital de Salvador, Bahia, Brasil. Revista Brasileira de Pesquisas Médicas e Biológicas, 11:49-52.

BEIGUELMAN, B.; PINTO Jr., W.; DALL'AGLIO, F. F.; SILVA, E. \& VOZZA, J. A., 1968. G-6-PD deficiency among lepers and healthy people in Brazil. Acta Genetica, 18:159-162.

BEUTLER, E., 1959. The hemolytic effect of primaquine and related compounds: A review. Blood, 14:103-139.

BEUTLER, E., 1983. Glucose-6-phosphate dehydrogenase deficiency. In: The Metabolic Basis of Inherited Disease (J. B. Stambury, J. B. Wyngaarden, D. S. Fredrikson, J. L. Goldstein \& M. S. Brown, eds.), pp. 1629-1653, New York: McGraw-Hill.

BEUTLER, E., 1994. G-6-PD deficiency. Blood, 84: 3613-3636.
BEUTLER, E.; GAETANI, G.; DERKALOUSTION, V.; LUZZATO, L.; NIWA, S.; PANNICH, V.; SODEINDE, O.; BELSEY, M.; KULIEV, A. M.; MODELL, B. \& SHAH, P. M., 1989. Glucose-6-phosphate dehydrogenase deficiency. Bulletin of the World Health Organization, 76:601-611.

BREWER, G. J.; TARLOV, A. R. \& ALVIG, A. S., 1962. The methemoglobin reduction test of primaquine type sensivitiy of erythrocytes. A simplified procedure for detecting a specific hyper-susceptibility to drug hemolysis. JAMA, 5:126-128.

BUENO, M. F. G., 1993. Memória fotográfica de Bragança Paulista. Cadernos do Centro de Memória Regional, vol. 1. Bragança Paulista: Editora da Universidade São Francisco.

CARRONS, J. L. V.; ZARZA, R. \& AYMERICH, J. M., 1997. Análisis molecular del déficit de glucosa-6fosfato deshidrogenase. Sangre, 42:391-398.

COMPRI, M. B.; POLIMENO, N. C.; STELLA, M. B. \& RAMALHO, A. S., 1996. Programa comunitário de hemoglobinopatias hereditárias em população estudantil brasileira. Revista de Saúde Pública, 30:187-195.

CREMESP (Conselho Regional de Medicina do Estado de São Paulo), 1996. Código de Ética Médica. 
In: Ética Médica (A. Pereira Filho, org.), pp.117124, São Paulo: Editora do Círculo do Livro.

CYRO Jr., A. \& ASTRINO Jr., A., 1904. Anuário de Bragança Paulista para 1904. São Paulo: Editora Andrade \& Mello.

GARLIPP, C. R. \& RAMALHO, A. S., 1988. Aspectos clínicos e laboratoriais da deficiência de desidrogenase de 6-fosfato de glicose (G-6-PD) em recémnascidos brasileiros. Revista Brasileira de Genética, 11:717-728.

HAMEL, A. R. \& SAAD, S. T. O., 1998. Caracterização Molecular das Variantes de G-6-PD em Doadores de Sangue da Fundação Centro de Hemoterapia e Hematologia do Pará. Projeto de Qualificação de Doutorado, Campinas: Instituto de Biologia, Universidade Estadual de Campinas.

LEWGOY, F. \& SALZANO, F. M., 1965. Dinâmica do gene que condiciona a deficiência de G-6-PD na população de Porto Alegre. Ciência e Cultura, 17: 152.

LUZZATO, L. \& MEHTA, A., 1995. Glucose-6-phosphate dehydrogenase deficieny. In: The Metabolic and Molecular Basis of Inherited Disease (C. R. Scriver, A. L. Beaudet, W. S. Sly \& D. Valle, eds.), pp. 3367-3398, New York: McGraw-Hill.

MANIATIS, T.; FRITSCH, E. F. \& SAMBROOCK, J. 1989. Molecular Cloning, a Laboratory Manual. New York: Spring Harbor.

MARQUES, J. \& CAMPOS, J. O., 1975. Incidência da deficiência de glicose-6-fosfato desidrogenase em negros de Minas Gerais. Revista da Associação Médica Brasileira, 21:111-112.

MARTINS, S. N. \& LAURITO, D., 1943. Bragança: 17631942. Coleção "São Paulo através da História”, vol. III, São Paulo: Editora Mário M. Ponzini \& Cia.

MODELL, B. \& KULIEV, A., 1998. The history of Community Genetics: The contribution of the haemoglobin disorders. Journal of Community Genetics, 1:3-11.

MOREIRA, A. S.; ARENDITE, E. J. \& MATTOS, F. A. M., 1997. Economia Regional: Bragança Paulista. Cadernos do Instituto Franciscano de Antropologia, vol. 17, Bragança Paulista: Editora da Universidade São Francisco.

ORITA, M.; IWAHANA, H.; KANAZAWA, K. \& SEKIYA, T., 1989. Detection of polymorphism of human DNA by gel electrophoresis as a single strand conformation polymorphisms. Proceedings of the $\mathrm{Na}$ tional Academy of Sciences, 86:2766-2770.

PAIVA E SILVA, R. B. \& RAMALHO, A. S., 1997. Riscos e benefícios da triagem genética: $\mathrm{O}$ traço falciforme como modelo de estudo em uma população brasileira. Cadernos de Saúde Pública, 13:285-294.

POGGI, V.; TOWN, M.; FOULFES, N. S. \& LUZZATO, L., 1990. Identification of a single base in a new human mutant glucose-6-phosphate dehydrogenase gene by polymerase-chain reaction amplification of the entire coding region genomic DNA. Biochemical Journal, 271:157-160.

RAMALHO, A. S. \& BEIGUELMAN, B., 1976. Deficiência de desidrogenase de 6-fosfato de glicose (G-6PD) em doadores de sangue brasileiros. Folha Médica, 73:281-282.
RAMALHO, A. S., 1979. Estudo Médico de Polimorfismos Genéticos de Importância Clínica no Brasil. Tese de Livre Docência, Campinas: Faculdade de Ciências Médicas, Universidade Estadual de Campinas.

RAMALHO, A. S., 1981. Deficiência de desidrogenase de 6 -fosfato de glicose (G-6-PD) em recém-nascidos brasileiros. Revista da Associação Médica Brasileira, 27:343-345.

RAMALHO, A. S., 1986. As Hemoglobinopatias Hereditárias. Um Problema de Saúde no Brasil. Ribeirão Preto: Editora da Sociedade Brasileira de Genética.

RAMALHO, A. S.; TEIXEIRA, R. C.; TEIXEIRA, P. A.; COMPRI, M. B.; STELLA, M. B. \& POLIMENO, N. C., 1996. Genética e Saúde Pública no Brasil: Os programas comunitários de hemoglobinopatias hereditárias. Anais da Academia Nacional de Medicina, 156:13-18.

RIVERO, M. E. J.; DINIZ, E. M. A.; NONOYAMA, K.; BARRETTO, O. C. O. \& VAZ, F. A. C., 1981. Deficiência de glicose-6-fosfato desidrogenase em recém-nascidos. Pediatria, 3:214-216.

SAAD, S. T. O.; SALLES, T. S. I.; CARVALHO, M. H. M. \& COSTA, F. F., 1997. Molecular characterization of glicose-6-phosphate dehydrogenase in Brazil. $\mathrm{Hu}$ man Heredity, 47:17-21.

SALDANHA, P. H.; NOBREGA, F. C. \& MAIA, J. C. C., 1969. Distribution and heredity of erythrocyte G6-PD activity and electrophoretic variants among different racial groups at São Paulo, Brazil. Journal of Medical Genetics, 6:48-54.

SALZANO, F. M. \& FREIRE-MAIA, N. 1970. Problems in Human Biology. A Study of Brazilian Populations. Detroit: Wayne State University Press.

SEGRE, C. A. M., 1971. Contribuição ao Estudo da Importância da Deficiência de Glicose-6-Fosfato Desidrogenase como Causa de Icterícia Neonatal. Tese de Doutorado, São Paulo: Escola Paulista de Medicina.

SENA, L. L. A. \& RAMALHO, A. S., 1985. Clinical evaluation of glicose-6-phosphate dehydrogenase deficiency in a Brazilian population. Revista Brasileira de Genética, 8:89-96.

SPARKS, R. S.; BALLUDA, M. C. \& TOWNSEND, D. E., 1969. Cellulose acetate electrophoresis of human G-6-PD. Journal of Laboratorial and Clinical Medicine, 73:531-534.

TEN KATE, L. P., 1998. Editorial. Journal of Community Genetics, 1:1-2.

WEATHERALL, D. J., 1972. The thalassemias. In: The Metabolic Basis of Inherited Disease (J. B. Stambury, J. B. Wyngaarden \& D. S. Friedrickson, eds.), pp. 1432-1449, New York: McGraw-Hill.

WEIMER, T. A.; SALZANO, F. M.; WESTWOOD, B. \& BEUTLER, E., 1998. G-6-PD variants in three South American ethnic groups: Population distribution and description of two new mutations. Human Heredity, 48:92-96.

WHO (World Health Organization), 1995. Glucose-6phosphate dehydrogenase deficiency. Report of a WHO working group. Bulletin of the Word Health Organization, 67:601-611. 